\title{
Focal cervical poliopathy causing juvenile muscular atrophy of distal upper extremity: a pathological study
}

\author{
KEIZO HIRAYAMA,* MASANORI TOMONAGA, $†$ KUNITAKA KITANO, \\ TATSUO YAMADA, ${ }^{*}$ SHIGEYUKI KOJIMA, ${ }^{*}$ KIMIHITO ARAI*
}

\begin{abstract}
From the Department of Neurology, Brain Research Institute, School of Medicine, Chiba University, Chiba,* Department of Neuropathology, Brain Research Institute, School of Medicine, University of Tokyo, Tokyo, $\dagger$ and Department of Neurology, Matsudo City Hospital, Matsudo, $\ddagger$ Japan
\end{abstract}

SUMMARY A new clinical entity under the name of "juvenile muscular atrophy of unilateral upper extremity" was first described in 1959. Although about 150 cases in Japan, and several additional cases in other countries, have been clinically reported in the literature, the pathology has remained unknown because of the benign course of the disease. The first necropsy findings are reported, obtained from a patient with this disease, who died of lung cancer at the age of 38, 23 years after the onset of the disease. The lesions existed only in the anterior horns of the spinal cord at C5 T1, particularly marked at $\mathrm{C} 7$ and $\mathrm{C} 8$, showing shrinkage and necrosis, degeneration of various degrees of large and small nerve cells, and mild gliosis. The pathological findings differ from those of reported cases of spinal vascular disorders, but some circulatory insufficiency in the territory of the spinal cord would seem to be suggested, although the underlying aetiology remains unknown.

In 1959 , one of the authors $(\mathrm{KH})^{1}$ reported 12 cases of "juvenile muscular atrophy of unilateral upper extremity," clinically differentiated from the known types of motor neuron disease. Our accumulated cases were 20 by $1963^{2}$ and 38 by $1972^{3}$ allowing further definition of its clinical features. About 150 clinical cases have since been reported in Japan, including many cases reported by Sobue. ${ }^{4}$ Cases have also been reported from Denmark, ${ }^{5}$ Holland, ${ }^{6}$ Singapore, ${ }^{7}$ and India. ${ }^{89}$ Very recently, similar cases have been reported from Malaysia ${ }^{10}$ in a letter to this journal.

Clinical features include the following: (1) It occurs predominantly in males of 15-25 years old. (2) Is usually sporadic, though rarely familial. (3) Manifests itself insidiously with muscular weakness and atrophy in the hand without any inducing factors such as infections and trauma, but its progression ceases in 2-3 years, mostly within 1-2 years. (4) The muscular atrophy is limited to the hand and forearm, excluding the brachioradialis muscle, thus showing a characteristic oblique amyotrophy over the forearm. (5) It shows cold paresis of the fingers (weakness exagger-

Address for reprint requests: Keizo Hirayama, MD, Department of Neurology, Brain Research Institute, School of Medicine, Chiba University, 1-8-1 Inohana, Chiba 280, Japan.

Received 24 January 1986 and in revised form 11 April 1986. Accepted 17 April 1986 ated by cold) and a fine and irregular tremor upon finger extension. (6) It predominates on one side (unilaterally in most cases, asymmetrical in some, and symmetrical in a few). (7) Muscle biopsy and needle electromyography show denervation, and may disclose subclinical changes even on the non-atrophic side. Nerve conduction velocity and cerebrospinal fluid are normal. (8) Except for a very rare and mild sensory abnormality over the dorsum of a hand, it lacks sensory disturbances, Horner's syndrome, abnormal deep tendon reflexes, pyramidal tract signs, and urinary disturbances. (9) Computed tomography with intrathecal metrizamide demonstrates a partial atrophy of the lower cervical cord, but routine radiography fails to show cervical spondylosis or disc herniation.

A quarter of a century has elapsed without pathological findings, due to the benign course of the disease. Recently we first obtained necropsy findings from a patient who died of lung cancer 23 years after the onset of this disease.

\section{Case report}

The patient was a 38 year old right handed male. The past medical history is non-contributory, without trauma. The family history includes a brother, 5 years younger, with muscular atrophy in the right hand which developed at the age of 13 years but ceased progression in about 6 months.

History of present illness In 1959, at the age of 15 years, the 

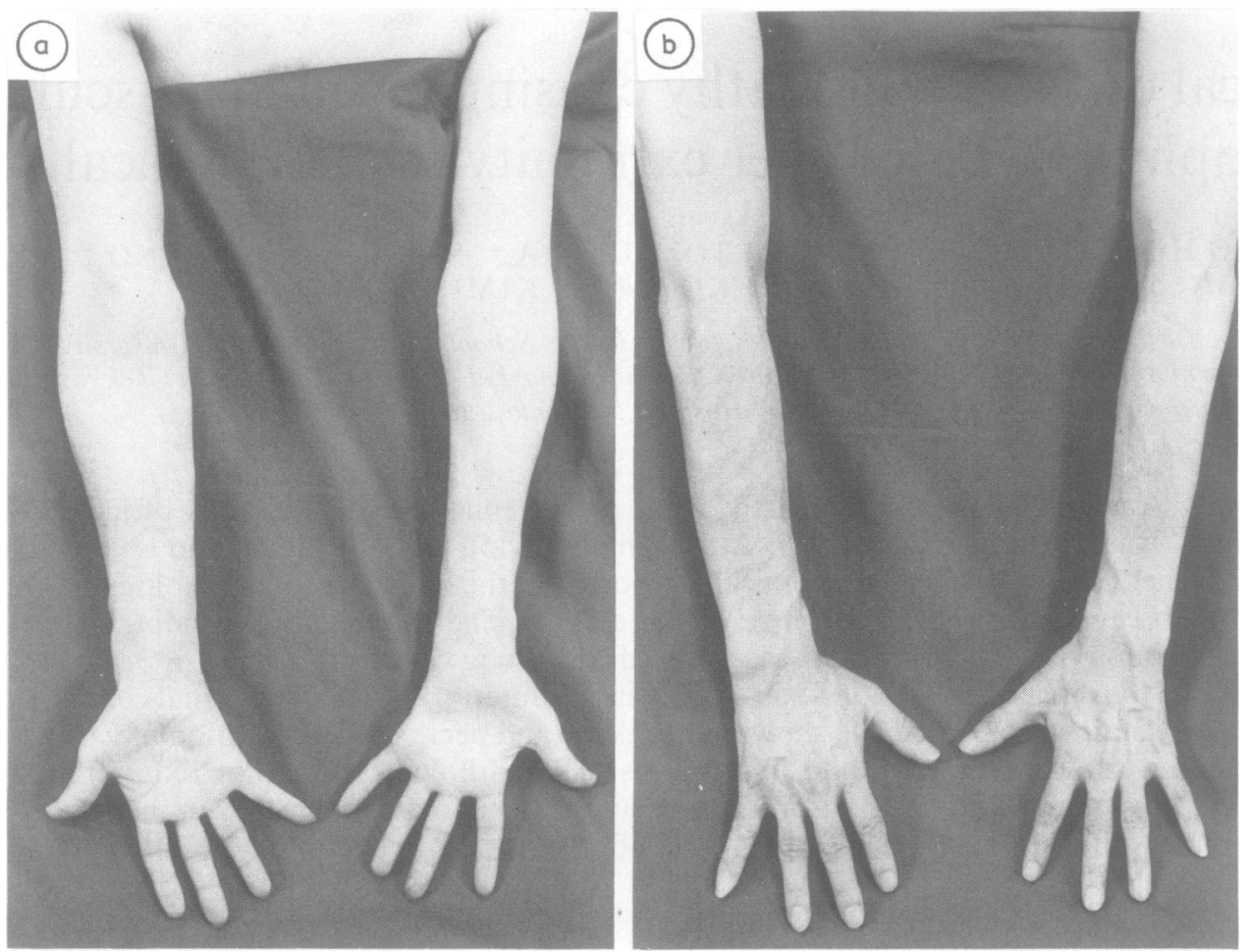

Fig 1 Muscular atrophy in the present case. The atrophy was limited to the left hand and forearm, sparing the hrachioradialis muscle. The right intrinsic hand muscles also showed mild atrophy.

patient noted weakness in his left hand upon braking a motor cycle. His hand grip became weaker thereafter, with atrophy in the hypothenar eminence and the first dorsal interosseus muscle, which stopped progressing in about a year. In 1961, at the age of 17 years, he was examined in another institute, but no clear diagnosis was made otht: than muscular atrophy. He also noted a fine tremor and cold paresis in his left hand. His condition had remained unchanged and untreated.

In May, 1980, at the age of 35, he noted a mild atrophy in his right first dorsal interosseus muscle and fatiguability of the right hand on writing. In August, 1980, he was admitted to the Department of Neurology (Prof Hirayama) in Chiba University.

Neurological findings on admission The left forearm and small hand muscles, except for the brachioradialis, showed the characteristically localised atrophy and weakness. The right small hand muscles also showed mild atrophy (fig 1). These were associated with a mild hypotonia at the wrists and hands. The fingers showed asynchronous, irregular, and fine tremors upon extension. The deep tendon reflexes were all symmetrically normal, without Babinski’s sign. Ataxia, extrapyramidal signs, sensory disturbances, Horner's sign, and abnormalities in sweating and urination were all absent. Laboratory data The plain cervical spine radiographs showed no abnormalities. The cerebrospinal fluid was normal. Queckenstedt's test was negative. Needle electro- myography showed neurogenic changes in the atrophic muse⿳⺈ cles, more marked on the left. Peripheral motor nerve con duction velocities were normal in the four extremities. A biopsy specimen of the left flexor carpi ulnaris muscle showed neurogenic changes. Myelography disclosed a slightly decreased anteroposterior diameter of the lower cervical cord.

Progress note The signs and symptoms had remained unchanged from August, 1980 until September, 1982 at the age of 38 , when he developed a dry cough. He was admitted to the Department of Medicine, Matsudo City Hospital, with the diagnosis of a mediastinal tumour. On October 6 he developed neurological symptoms due to cerebral metastases shown on a CT scan. Chemotherapy was started on October 29. His cerebral symptoms progressed further in November and he expired on December 6 . In the meantime, ${ }^{99} \mathrm{Tc}$ bone scanning of the whole body had demonstrated abnormal uptake areas in the left 12th rib, the 5th lumbar vertebra, and the right hip joint. Lymph node biopsy through a mediastinoscope suggested a squamous cell carcinoma.

\section{Neuropathological findings}

The necropsy was performed 4 hours after death. General pathology revealed that the left upper pulmonary lobe contained a primary adenocarcinoma. The aorta showed no atheroma except at the bifurcation nor thickening of the wall 

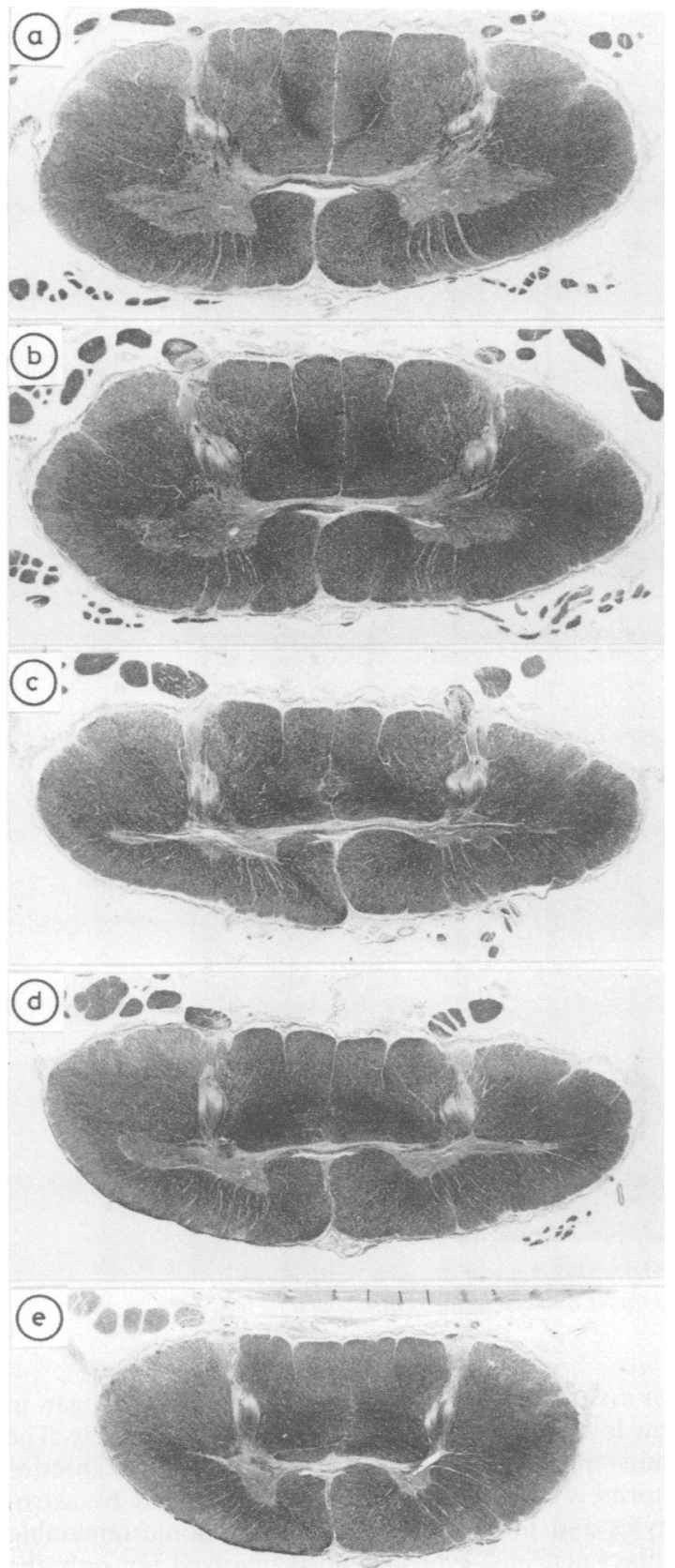

Fig 2 Cervical enlargement of the spinal cord. $(a): C 5,(b)$ : C6, (c): C7, (d): C8, (e): TI. The anterior horns at C7 and C8 are markedly shrunken in anteroposterior diameters. The milder changes extended up to C5 and down to TI. The left side of each figure is the patient's right side. Klüver-Barrera. $(\times 5$.) throughout its entire length. The heart was normal. The spinal canal had a smooth inner surface without any deformities or protrusions.

Macroscopic findings The brain weighed $1,500 \mathrm{~g}$. The left frontal, left parietal, right occipital lobes and the right cerebellum contained metastases. There was another metastasis at the 5th lumbar vertebra without any intrathecal invasion. The arachnoid of the spinal cord showed no clouding or thickening. The spinal cord seemed flattened anteroposteriorly at $\mathrm{C} 7$ and $\mathrm{C} 8$ levels. The anterior roots were slightly thinned at C5 and C6, and markedly so at C7-T1, without obvious asymmetries. The spinal cord and roots showed no vascular abnormalities.

Histological findings The cerebral tissues around the metastatic tumours showed oedema with a mild gliosis, but the rest of the brain was normal. Examination of the spinal cord by haematoxylin-eosin, elastic van Gieson, Klüver-Barrera, Bodian and Holzer stains revealed the most severe changes at the levels of $\mathrm{C7}$ and $\mathrm{C} 8$. Both anterior horns had shrunk to less than half of the normal anteroposterior diameters, especially on the left (fig 2). The number of both large and small nerve cells had decreased, and the remaining nerve cells showed various degenerative changes including lipofuscin accumulation, chromatolysis and shrinkage (fig 3 ). The neuropil was partially destroyed and showed a slight astrogliosis in the peripheral portion of the anterior horn. However, there were no macrophages, and no cavity formation. Vascular proliferation was absent. Iron pigment was not found by Perl's stain, and amyloid was also absent with the Congo red stain. The posterior horns were normal. The white matter was well preserved. The anterior roots on both sides showed thinning due to loss of myelinated fibres in the intra- and extra-medullary portions. The posterior roots were normal. A mild thickening of the arachnoid was present on the anterior surface of the cord, particularly around the outlets of the roots.

The changes extended upwards to $\mathrm{C} 5$ and downwards to T1 levels, but they were less marked at these levels. The cytoplasm of a few nerve cells at $\mathrm{C} 5$ and $\mathrm{T} 1$ showed a round basophilic inclusion, which had a clear margin with a thin halo and diameter of $50-80 \mu$.

The brachial plexus showed a moderate loss of nerve fibres and slight fibrosis in the C8 trunk, but only patchy changes in other trunks. The inferior cervical sympathetic ganglia showed a decrease of the number of nerve cells, with proliferation of capsule cells. The thoracic sympathetic chains were also involved, but not to a severe extent.

Other levels of the spinal cord were normal, except at the 5th lumbar level, where the large neurons of the right anterior horn showed central chromatolysis, perhaps related to the cancer metastasis in the 5th lumbar vertebra. The nerve cells did not contain intracytoplasmic inclusions. The neuropil appeared normal, without glial reaction.

The intra- and extra-medullary vascular system of the spinal cord showed no abnormalities.

\section{Discussion}

From his clinical case studies of this disease, Hirayama ${ }^{3}$ inferred pathological changes at $\mathrm{C} 6,7,8$, and T1. The present necropsy study demonstrated 

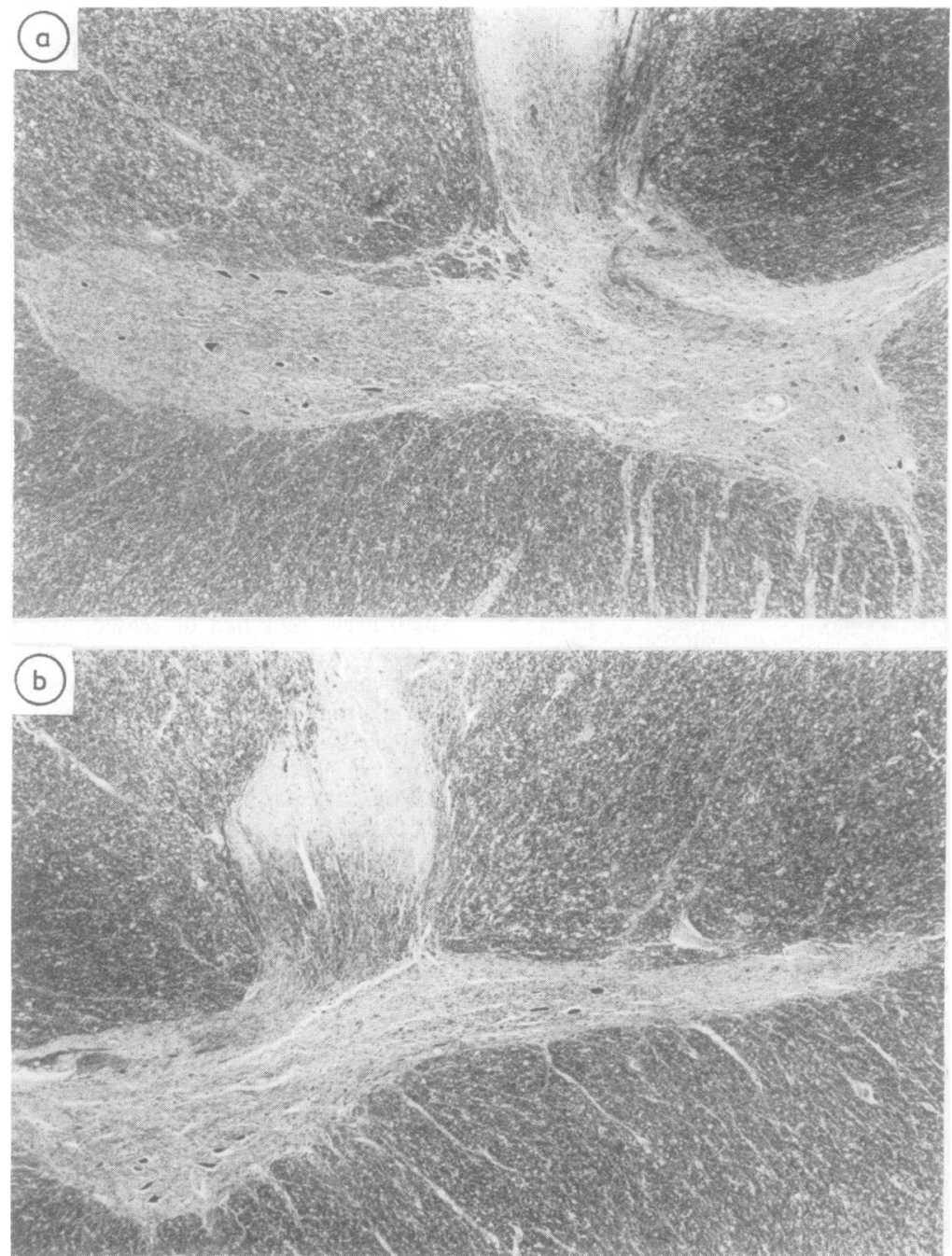

Fig 3 Anterior horns of C8. (a): right, (b): left. Shrinkage of the gray matter with decreased numbers of large and small neurons, more marked in the central part. Klüver-Barrera. ( × 32.)

lesions at $\mathrm{C} 5-\mathrm{T} 1$, milder at $\mathrm{C} 5$ and $\mathrm{C} 6$, giving a good clinicopathological correlation.

Some authors, on clinical grounds, consider this disease as a form of motor neuron disease, ${ }^{7}$ as we ourselves once did. However, the present pathological findings do not fall into the category of motor neuron degenerative disease. Although basophilic inclusion bodies are occasionally found in juvenile motor neuron diseases, ${ }^{11-13}$ they were found only at the upper (C5) and the lower extremes of the lesions (T1) in the present case.

The peculiar case of Garcin and Gruner ${ }^{14}$ had features both of motor neuron degenerative disease and of a vascular disorder. The muscle atrophy began in the lower extremities and ascended progressively. The most marked lesions were seen in the lumbar anterior horns, with central cavitation surrounded by astrocytes and proliferated vessels, with some remaining intact neurons. Fibrous gliosis involved not only the anterior horns but also their surrounding white matter.

In cases with long survival of an attack of acute anterior poliomyelitis, such as those described by Peers, ${ }^{15}$ one expects to see destruction of gray matter proportional to the loss of neurons and dense fibrous gliosis. In contrast, the usual clinical manifestations 
and the constancy of the levels affected in this disease, along with the relatively mild gliosis seen in our present case, bear no resemblance to the patterns seen in cases of previous poliomyelitis.

A tumour, a syrinx, or even a traumatic lesion in the lower cervical cord can cause muscular atrophy with a similar distribution to that seen in the present disease. However, the present necropsy study did not show such lesions. As for trauma, not only major cervical spinal injuries ${ }^{16}$ but also such minor injuries sustained in stretching the arms $^{17}$ or dressing ${ }^{18}$ may induce cord lesions. In such cases, tetraparesis will rapidly develop, and the lesions are most marked at C6, involving not only the anterior horns but also the adjacent white matter, including the anterior funiculi, parts of the lateral funiculi, and the anterior portion of the posterior funiculi. ${ }^{16-19}$ Repeated minor traumas can also cause cord injuries which are, however, difficult to substantiate. ${ }^{18}$ Some have reported delayed onset of neurological manifestations after trauma, ${ }^{20-22}$ but their clinical and pathological findings are entirely different from ours. A further point of difference from cases of delayed traumatic myelopathy is that some of our cases show a familial tendency to the disease.

Among the vascular lesions of the spinal cord, this disease most resembles the "téphromalacie antérieure" of Marie and Foix ${ }^{23}$ with infarcts confined to the anterior horns at C7-T1. However, the latter occurs among elderly persons, and its pathology consists of infarction, resulting from occlusion of the spinal arteries due to syphilitic arteritis or arteriosclerosis.

Spinal vascular lesions, segmentally localised at the lower cervical levels, were reported in four out of 21 cases of arteriosclerotic myelopathy in the aged by Gruner et al. ${ }^{24}$ In their transverse sections of the cord, the necrotic changes involved not only the anterior horns but also the anterior portion of the posterior funiculi. After a study of spinal cords of the aged. Lapresle $^{25}$ stated that the anterior horn, particularly the neurons in its central portion, was the most sensitive to spinal circulatory disorders. Gilles et al ${ }^{26}$ observed in children that a transient cardiac arrest or arterial hypotension damaged the anterior more than the posterior horns, and the central more than the peripheral portions of the anterior horn. Our case seems to have pathological changes similar to those reported in these cases. However, in these two and other reports, ${ }^{27-32}$ the lesions secondary to systemic circulatory failure are characteristically confined to the lower (lumbar) spinal cord, unlike those in our case.

Necropsy studies in cervical spondylosis by Brain et $\mathrm{al}^{\mathbf{3 3}}$ and in disc herniation by Mair et al ${ }^{34}$ showed lesions at mid-cervical levels, involving the anterior portion of the posterior funiculi, the anterior horns, and the adjacent intermediate zone of the lateral funiculi, all lined on the transverse axis of the spinal cord. Breig et $\mathrm{l}^{35}$ postulated that forward bending of the neck would flatten the cord from front to back, stretching the vessels sideways; this in turn could induce a secondary vascular disorder. A role of the dentate ligaments in inducing cord lesions was emphasised in cervical spondylosis by Cusick et al $^{36}$ and in multiple sclerosis by Oppenheimer. ${ }^{37}$ Yada et al $^{38}$ recently proposed as a cause of cervical myelopathy an over-stretch mechanism associated with compression of the dura and cord against the vertebrae during neck flexion. These hypotheses are interesting when considering the pathogenesis of the present disease, but these lesions, different from our case, involve the white matter, producing long tract signs.

The pathological findings in the present case certainly differ not only from those of other disorders but also from those of reported cases of spinal vascular disorders; but they still seem to suggest a circulatory insufficiency in the lower cervical cord as the most likely pathogenesis. As long as the underlying aetiology remains unknown this disease may be referred to clinico-pathologically as "juvenile focal cervical poliopathy."

The present research was supported in part by the Research Committee of CNS Degenerative Disease of the Ministry of Health and Welfare of Japan. The authors thank Dr David R Oppenheimer, Oxford, for his help; Prof Kenichi Uemura, for help in the English translation of the paper and Mr Hitoshi Nagase and $\mathrm{Mr}$ Naoo Aikyo for the histological preparations.

\section{References}

1 Hirayama K, Toyokura Y, Tsubaki T. Juvenile muscular atrophy of unilateral upper extremity; a new clinical entity. Psychiat Neurol Jap 1959;61:2190-7.

2 Hirayama K, Tsubaki T, Toyokura Y, Okinaka S. Juvenile muscular atrophy of unilateral upper extremity. Neurology 1963;13:373-80.

3 Hirayama K. Juvenile non-progressive muscular atrophy localised in the hand and forearm-observation in 38 cases. Clin Neurol (Tokyo) 1972;12:313-24.

4 Sobue I, Saito N, Iida M, Ando K. Juvenile type of distal and segmental muscular atrophy of upper extremities. Ann Neurol 1978;3:429-32.

5 Pilgaard S. Unilateral juvenile muscular atrophy of upper limbs. Acta Orthop Scand 1968;39:327-31.

6 Compernolle T. A case of juvenile muscular atrophy confined to one upper limb. Eur Neurol 1973;10: 237-42.

7 Loong SC, Yap MHL, Nei IP. An unusual form of 
motor neuron disease. In: 4th Asian and Oceanic Congress of Neurology. Bangkok. Sompong Press 1975:35 (Abstr).

8 Singh N, Sachdev KK, Susheela AK. Juvenile muscular atrophy localised to arms. Arch Neurol 1980;37:297-9.

9 Gourie-Devi M, Suresh TG, Shankar SK. Monomelic amyotrophy. Arch Neurol 1984;41:388-94.

10 Tan CT. Juvenile muscular atrophy of distal upper extremities. $J$ Neurol Neurosurg Psychiatry 1985;48:285-6.

11 Nelson JS, Prensky AL. Sporadic juvenile amyotrophic lateral sclerosis. Arch Neurol 1972;27:300-6.

12 Oda M, Akagawa N, Tabuchi Y, Tanabe H. A sporadic juvenile case of amyotrophic lateral sclerosis with neuronal intracytoplasmic inclusions. Acta Neuropathol 1978;44:211-6.

13 Tsujihata $\mathbf{M}$, Taguchi $\mathrm{H}, \mathrm{Oku}$ Y, Takamori $\mathbf{M}$, Terao $\mathbf{H}$. A sporadic case of juvenile amyotrophic lateral sclerosis. Clin Neurol (Tokyo) 1978;18:82-8.

14 Garcin R, Gruner J. Nécrose cavitaire des cornes antérieures de la moelle au cours d'un syndrome réalisant une forme pseudo-polynévritique de sclérose latérale amyotrophique. Presse Med 1953;61:1723-4.

15 Peers JH. The pathology of convalescent poliomyelitis in man. Am J Pathol 1943;19:673-95.

16 Foo D, Bignami A, Rossier AB. Posttraumatic anterior spinal cord syndrome: Pathological studies of two patients. Surg Neurol 1982;17:370-5.

17 Grinker RR, Guy CC. Sprain of cervical spine causing thrombosis of anterior spinal artery. JAMA 1927;88:1140-2.

18 Hughes JT, Brownell B. Cervical spondylosis complicated by anterior spinal artery thrombosis. Neurology 1964;14:1073-7.

19 Tönnis D. Mangeldurchblutung als Ursache von Rückenmarksschädigungen. Münch Med Woch 1961;103: 1338-43, 1370-7.

20 Foerster O. Die traumatisshen Läsionen des Rückenmarkes auf Grund d'r Kriegserfahrungen. In: Bumke O, Foerster O, eds. Handbuch der Neurologie. Berlin: Springer 1929; Ergänzungsband II-Teil: 1721-927.

21 Lhermitte J, Rober B de. La myélomalacie tardive par effort. Rev Neurol (Paris) 1942;74:175-6.

22 André M. Sur une nécrose œdémateuse de la moelle, plusieurs jours après un traumatisme fermé apparemment sans gravité. J Belge Neurol et Psychiatr 1946;46:439-49.

23 Marie P, Foix Ch. L'atrophie isolée non progressive des petits muscles de la main. Téphromalacie antérieure. Nouvelle Iconographie de la Salpêtrière 1912;25: 353-63, 427-53.

24 Gruner J, Lapresle J. Etude anatomo-pathologique des médullopathies d'origine vasculaire. Rev Neurol (Paris) 1962;106:592-631.

25 Lapresle J. Sur quelques aspects neuropathologiques des troubles de la circulation dans la moelle épinière. Bull Schweiz Akad Med Wiss 1969;24:512-29.

26 Gilles FH, Nag D. Vulnerability of human spinal cord in transient cardiac arrest. Neurology 1971;21:833-9.

27 Moersch FP, Sayre G. Neurologic manifestations associated with dissecting aneurysm of the aorta. JAMA 1950;6144:1141-8.

28 Kepes JJ. Selective necrosis of spinal cord gray matter. A complication of dissecting aneurysm of the aorta. Acta Neuropathol 1965;4:293-8.

29 Herrick MK, Mills PE Jr. Infarction of spinal cord. Arch Neurol 1971;24:228-41.

30 Azzarelli B, Roessmann U. Diffuse "anoxic" myelopathy. Neurology 1977;27:1049-52.

31 Slumberg P, Byrne E. Hypotensive central infarction of the spinal cord. J Neurol Neurosurg Psychiatry 1980;43:751-3.

32 Jellinger K. Pathogenese und Morphologie spinaler Durchblutungs-störungen. Zentralbl Neurochirurgie 1980;41:3-18.

33 Brain WR, Northfield D, Wilkinson M. The neuro- $\square$ logical manifestations of cervical spondylosis. Brain $\overline{\mathrm{D}}$ 1952;75:187-225.

34 Mair WGP, Druckman R. The pathology of spinal cord $\frac{\mathbb{D}^{+}}{\mathrm{C}}$ lesions and their relation to the clinical features in protrusion of cervical intervertebral disc. Brain 1953;76:70-91.

35 Breig A, Turnbull I, Hassler O. Effects of mechanica stress on the spinal cord in cervical spondylosis. A study on fresh cadaver material. $J$ Neurosurg 1966;25:45-54.

36 Cusick JF, Ackmann JJ, Larson SJ. Mechanical and physiological effects of dentatotomy. J Neurosurg 1977;46:767-75.

37 Oppenheimer DR. The cervical cord in multiple sclerosis. Neuropathol Appl Neurobiol 1978;4:151-62.

38 Yada K, Tachibana S, Okada K. Spinal cord lesion due to relative imbalance of cervical spine and cervical cord (author's translation). In: 1981 Annual Report of "Prevention and Treatment for the Congenital Anomalies of the Spine and Spinal Cord," The Ministry of Health and Welfare of Japan, 1982:48-55. 